\title{
The Mitochondria-Targeted Antioxidant MitoQ Modulates Mitochondrial Function and Endoplasmic Reticulum Stress in Pancreatic $\beta$ Cells Exposed to Hyperglycaemia
}

\author{
Irene Escribano-Lopez ${ }^{\mathrm{a}} \quad$ Celia Bañuls ${ }^{\mathrm{a}} \quad$ Noelia Diaz-Morales ${ }^{\mathrm{a}}$ \\ Francesca lannantuoni ${ }^{a}$ Susana Rovira-Llopis ${ }^{a} \quad$ Ramon Gomis $^{b}$ \\ Milagros Rocha ${ }^{\mathrm{a}, \mathrm{c}}$ Antonio Hernandez-Mijares ${ }^{\mathrm{a}, \mathrm{d}, \mathrm{e}} \quad$ Michael P. Murphy $^{\mathrm{f}}$ \\ Victor M. Victor ${ }^{\mathrm{a}, \mathrm{c}, \mathrm{g}}$
}

\begin{abstract}
aService of Endocrinology and Nutrition, University Hospital Doctor Peset, Foundation for the Promotion of Health and Biomedical Research in the Valencian Region (FISABIO), Valencia, Spain, ${ }^{b}$ Ciberdem - Department of Endocrinology and Nutrition, Hospital Clinic, School of Medicine, University of Barcelona, Diabetes and Obesity Research Laboratory, Institut d'Investigacions Biomèdiques August Pi i Sunyer (Idibaps), Barcelona, Spain, 'Ciberehd - Departments of Pharmacology and Physiology, University of Valencia, Valencia, Spain, Institute of Health Research INCLIVA, University of Valencia, Valencia, Spain, ${ }^{e}$ Department of Medicine, University of Valencia, Valencia, Spain, ${ }^{\mathrm{f}} \mathrm{MRC}$ Mitochondrial Biology Unit, University of Cambridge, Cambridge, United Kingdom, 9Department of Physiology, University of Valencia, Valencia, Spain
\end{abstract}

\section{Key Words}

Pancreatic $\beta$ cells $\bullet$ Oxidative stress $•$ Mitochondrial dysfunction - ER stress $•$ Type 2 Diabetes - MitoQ

\footnotetext{
Abstract

Background/Aims: Mitochondria-targeted antioxidants such as mitoquinone (MitoQ) have demonstrated protective effects against oxidative damage in several diseases. The increase in reactive oxygen species (ROS) production during glucose metabolism in $\beta$ cells can be exacerbated under hyperglycaemic conditions such as type 2 diabetes (T2D), thus contributing to $\beta$ cell function impairment. In the present work, we aimed to evaluate the effect of MitoQ on insulin secretion, oxidative stress, endoplasmic reticulum (ER) stress and nuclear factor kappa $B$ (NFKB) signalling in a pancreatic $\beta$ cell line under normoglycaemic (NG, $11.1 \mathrm{mM}$ glucose), hyperglycaemic (HG, $25 \mathrm{mM}$ glucose) and lipidic (palmitic acid (PA), $0.5 \mathrm{mM}$ ) conditions. Methods: We incubated the pancreatic $\beta$ cell line INS-1E with or without MitoQ $(0.5 \mu \mathrm{M})$ under

I. Escribano-Lopez and C. Bañuls contributed equally to this work. 


\section{Cellular Physiology Cell Physiol Biochem 2018;52:186-197 \\ \begin{tabular}{ll|l}
\cline { 2 - 2 } and Biochemistry $10.33594 / 000000013$ & $\begin{array}{l}\text { D } 2019 \text { The Author(s). Published by } \\
\text { Published online: } 28 \text { February } 2019\end{array}$ \\
\cline { 2 - 3 } & Cell Physiol Biochem Press GmbH\&Co. KG
\end{tabular} \\ Escribano-Lopez et al.: MitoQ Alleviates Endoplasmic Reticulum Stress Under \\ Hyperglycaemia}

NG, HG and PA conditions. We then assessed the following parameters: glucose-induced insulin secretion, $\mathrm{O}_{2}$ consumption (with a Clark-type electrode); mitochondrial function, oxidative stress parameters and calcium levels (by fluorescence microscopy); ER stress markers and NFkB-p65 protein levels (by western blotting). Results: MitoQ increased insulin secretion and prevented the enhancement of ROS production and $\mathrm{O}_{2}$ consumption and decrease in GSH levels that are characteristic under HG conditions. MitoQ also reduced protein levels of ER stress markers (GRP78 and P-elF2 $\alpha$ ) and the proinflammatory nuclear transcription factor NFkB-p65, both of which increased under HG. MitoQ did not significantly alter ER stress markers under lipidic conditions. Conclusion: Our findings suggest that treatment with MitoQ modulates mitochondrial function, which in turn ameliorates endoplasmic reticulum stress and NFKB activation, thereby representing potential benefits for pancreatic $\beta$ cell function.

\section{Introduction}

(C) 2019 The Author(s). Published by Cell Physiol Biochem Press GmbH\&Co. KG

During the onset of type 2 diabetes (T2D), glucose homeostasis is altered due to impairment of the compensatory response of $\beta$ cells [1]. In addition to the destruction of pancreatic $\beta$ cells $[2,3]$, T2D is also associated with oxidative stress and mitochondrial dysfunction [4-6], with mitochondria representing the main source of reactive oxygen species (ROS) in mammalian cells. In this way, the increase in ROS levels in pancreatic $\beta$ cells under hyperlipidaemia and hyperglycaemia is one of the key events leading to the impairment of $\beta$ cell function in T2D [7], although the exact underlying mechanisms are yet to be elucidated.

Under normal conditions, pancreatic $\beta$ cells generate ATP by metabolizing glucose via glycolysis and through the tricarboxylic acid cycle. During this process, ROS are released and counteracted by antioxidant cell defences. Moreover, $\beta$ cells modulate blood glucose concentration by releasing insulin, which occurs when the enhanced metabolism of glucose in $\beta$ cells increases the ATP/ADP ratio and leads to a rapid influx of $\mathrm{Ca}^{2+}$, which in turn triggers the release of insulin. The hyperglycaemic (HG) conditions typical in T2D patients lead to increased ROS production $[8,9]$, which can be exacerbated under hyperlipidaemia; oxidation of free fatty acid-derived acetyl CoA by the TCA cycle and $\beta$-oxidation are enhanced, which leads once again to increased ROS production [10]. As pancreatic $\beta$ cells are highly susceptible to oxidative damage [11], antioxidant therapies that improve or avoid oxidative stress may help ameliorate damage.

Oxidative stress has also been related to endoplasmic reticulum (ER) stress under insulin resistance conditions [12]. In fact, ER stress plays an important role in $\beta$ cell impairment under both hyperlipidaemic and hyperglycaemic conditions $[13,14]$, and constitutes a key mediator of $\beta$ cell apoptosis [15]. Furthermore, it has been reported that ER stress signalling might be triggered by oxidized LDL through the induction of P-eIF2 $\alpha$, ATF6 and IRE1 $\alpha$ in vascular cells [16]. In addition, oxidative stress can activate $\mathrm{NF \kappa B}$, leading to changes in proinflammatory gene expression, eventually inducing cardiovascular impairment [17].

Therefore, therapies that decrease mitochondrial impairment, oxidative stress and, consequently, ER stress may be effective in the treatment of T2D and its deleterious effects [4]. For this reason, mitochondria-targeted antioxidants are emerging as potential protective therapies against oxidative damage in cardiovascular diseases, T2D and other conditions $[18,19]$. The most widely used mitochondria-targeted antioxidant is mitoquinone (MitoQ), an ubiquinone derivate that specifically targets mitochondria by covalent attachment to a lipophilic triphenylphosphonium (TPP) cation $[20,21]$ and which can prevent lipid peroxidation. Due to the mitochondrial membrane potential $(\Delta \Psi \mathrm{m})$, this cation is accumulated within mitochondria inside the cells.

Therefore, the aim of the current study was to evaluate the extent of the potentially beneficial effects of the mitochondria-targeted antioxidant Mito $Q$ on insulin secretion, oxidative stress, ER stress and NFKB in the pancreatic $\beta$ cell line INS-1E - a widely used $\beta$-cell surrogate - under normoglycaemic (NG), HG and lipidic conditions. 


\section{Cellular Physiology Cell Physiol Biochem 2018;52:186-197 \\ \begin{tabular}{l|l|l}
\hline DOI: 10.33594/000000013 & (2019 The Author(s). Published by
\end{tabular}

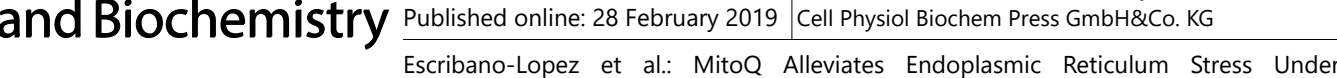 \\ Materials and Methods \\ Hyperglycaemia}

\section{Cell culture and treatments}

The pancreatic $\beta$ cell line INS-1E was cultured in a humidified chamber with $5 \% \mathrm{CO}_{2}$ in RPMI-1640 medium (Biowest, Nuaillé, France) at $11.1 \mathrm{mM}$ glucose supplemented with $5 \%$ (vol./vol.), heat-inactivated foetal calf serum (FCS), $10 \mathrm{mM}$ HEPES, $2 \mathrm{mM}$ L-glutamine, $100 \mathrm{U} / \mathrm{mL}$ penicillin, $100 \mu \mathrm{g} / \mathrm{mL}$ streptomycin, $1 \mathrm{mM}$ sodium pyruvate and $50 \mu \mathrm{M} \beta$-mercaptoethanol, as previously described [22]. All experiments were performed in cells from passages 40-50. After 4 days of pre-culture in a T75 flask, cells were transferred to T25 flasks or well plates and maintained a further 2 days at $11.1 \mathrm{mM}$ glucose (NG) or exposed to one of the following conditions for 24 hours: high glucose concentration (25 mM, HG) [23] or $0.5 \mathrm{mM}$ palmitate-BSA conjugate [24]. Upon 85\% confluency, cells were treated for 3 or 24 hours with $0.5 \mu \mathrm{M}$ MitoQ or decyl-TPP in order to evaluate the non-specific effects of MitoQ. Decyl-TPP is similar in hydrophobicity to MitoQ but without the ubiquinol antioxidant moiety [25].

\section{Cell viability assay}

Cell viability was assessed using the colorimetric MTT assay Kit (Roche Molecular Biochemicals, Mannheim, Germany) after several periods (from $1 \mathrm{~h}$ to $24 \mathrm{~h}$ ) of treatment with the mitochondria-targeted antioxidant and decyl-TPP. This colorimetric assay measures the activity of enzymes that reduce 3-(4, 5-dimethylthiazol-2-yl)-2, 5-diphenyltetrazolium bromide, a yellow tetrazole, to a purple formazan dye. Absorbance of dissolved formazan crystals was measured in a microplate spectrophotometer reader at 570 $\mathrm{nm}$. Data are displayed as a percentage of absorbance relative to that of the untreated cells.

Glucose-induced insulin secretion (GIIS)

INS-1E $\beta$ cells were seeded at a density of $0.5 \times 10^{6}$ cells/well in a 24 -well plate. Glucose-stimulated secretion was performed after 2 days of culture in RPMI growth medium in the presence or absence of PA $0.5 \mathrm{mM}(24 \mathrm{~h})$. During the last $3 \mathrm{~h}$, cells were exposed to $0.5 \mu \mathrm{M}$ MitoQ and then washed twice with Hanks' balanced salt solution (HBSS, Sigma Aldrich, Missouri, US). As a basal insulin secretion level, we used HBSS supplemented with $3 \mathrm{mM}$ glucose; and as a stimulated level we used HBSS supplemented with 15 $\mathrm{mM}$ glucose. The supernatants were then stored for subsequent determination of insulin levels using a rat insulin ELISA kit (Mercodia AB, Uppsala, Sweden). The inter- and intra-assay coefficients of variation were all under $10 \%$. Insulin secretion was normalized to total cellular protein.

\section{Measurement of $\mathrm{O}_{2}$ consumption}

INS-1E $\beta$ cells were detached by trypsinization, counted with a Scepter 2.0 cell counter (Millipore Iberica, Madrid, Spain), resuspended $\left(5 \times 10^{6}\right.$ cells $\left./ \mathrm{mL}\right)$ in HBSS and placed in a gas-tight chamber. Mitochondrial $\mathrm{O}_{2}$ consumption was then measured with a Clark-type $\mathrm{O}_{2}$ electrode (Rank Brothers, Bottisham, U.K.) [26]. An inhibitor of the electron transport chain, sodium cyanide $\left(10^{-3} \mathrm{~mol} / \mathrm{L}\right)$, was used to confirm that $\mathrm{O}_{2}$ consumption was mainly mitochondrial (95-99\%).

Membrane potential ( $\Delta \Psi \mathrm{m})$, ROS production, glutathione (GSH) and calcium levels measurement

Fluorescence probes tetramethylrhodamine methylester (TMRM; $\left.5 \times 10^{-6} \mathrm{~mol} / \mathrm{l}\right)$, MitoSOX $\left(5 \times 10^{-6}\right.$ mol/l), 2',7'-dichlorodihydrofluorescein diacetate (DCFH-DA; $5 \times 10^{-6} \mathrm{~mol} / \mathrm{l}$ ), 5-chloromethylfluorescein diacetate (CMFDA; $1 \times 10^{-6} \mathrm{~mol} / \mathrm{l}$ ), and (acetyloxy)methyl ester (Fluo-4 AM; $1 \times 10^{-6} \mathrm{~mol} / \mathrm{l}$ ) were employed to estimate $\Delta \Psi \mathrm{m}$, mitochondrial ROS, total ROS, GSH content and calcium levels, respectively. For these measurements, cells were seeded in 48-well plates and incubated for $30 \mathrm{~min}$ with the respective fluorescent probe. Fluorescence was then measured by fluorometry using a fluorescence microscope (IX81; Olympus) coupled to the static cytometry software "ScanR" (Olympus). Nuclei were visualized with Hoechst 33342. Measures of fluorescence are expressed in arbitrary units. Experiments were performed in triplicate and 16 images per well were recorded and analysed. All fluorochromes were purchased from Thermo Fisher Scientific, Waltham, US.

Western blotting (WB) 


\section{Cellular Physiology Cell Physiol Biochem 2018;52:186-197 \\ \begin{tabular}{ll|ll} 
and Biochemistry & $\begin{array}{l}\text { DOl: 10.33594/000000013 } \\
\text { Published online: } 28 \text { February } 2019\end{array}$ & $\begin{array}{l}\text { C 2019 The Author(s). Published by } \\
\text { Cell Physiol Biochem Press GmbH\&Co. KG }\end{array}$ \\
\cline { 2 - 3 }
\end{tabular} \\ Escribano-Lopez et al.: MitoQ Alleviates Endoplasmic Reticulum Stress Under \\ Hyperglycaemia}

Following the previously described treatments, total protein extracts from INS-1E $\beta$ cells were obtained by lysing on ice for $15 \mathrm{~min}$ with an extraction buffer ( $400 \mathrm{mM} \mathrm{NaCl}, 20 \mathrm{mM} \mathrm{HEPES} \mathrm{pH} \mathrm{7.5,} \mathrm{20 \%} \mathrm{Glycerol,} 0.1$ mM EDTA, $10 \mu \mathrm{M} \mathrm{Na}_{2} \mathrm{MoO}_{4}$ and $0.5 \%$, and Nonidet P-40) containing protease inhibitor mixture (10 mM NaF, $1 \mathrm{mM} \mathrm{Na}_{3} \mathrm{VO}_{4}, 10 \mathrm{mM} \mathrm{PNP}$, and $10 \mathrm{mM} \beta$-glycerolphosphate) and dithiothreitol $1 \mathrm{mM}$, and by performing centrifugation at $4^{\circ} \mathrm{C}$ for $15 \mathrm{~min}$. Concentration of the isolated supernatant-containing protein extract was determined using the BCA protein assay kit (Thermo Fisher Scientific, IL, US). Twenty-five micrograms of protein were resolved by sodium dodecyl sulfate polyacrylamide gel electrophoresis (SDS-PAGE) and then transferred to nitrocellulose membranes. After blocking, membranes were incubated overnight at $4^{\circ} \mathrm{C}$ with the following primary antibodies: anti-GRP78 rabbit polyclonal antibody (Abcam, Cambridge, MA), anti-P-eIF2 $\alpha$-pS52 rabbit polyclonal antibody (Life Technologies, California, US), anti-NFkB-p65 (phospho S536) rabbit polyclonal antibody (Abcam, Cambridge, MA) and anti-actin rabbit polyclonal antibody (Sigma Aldrich, Missouri, US). Blots were incubated with the secondary antibody HRP goat anti-rabbit (Millipore Iberica, Madrid, Spain) and developed for 2 min with ECL plus reagent (GE Healthcare, LC, UK) or Supersignal West Femto (Thermo Fisher Scientific, IL, US). The protein signal was detected by chemiluminescence and visualized in a Fusion FX5 acquisition system (Vilbert Lourmat, Marne La Valle'e, France). Images were analysed and quantified by densitometry using Bio1D software (Vilbert Lourmat, Marne La Valle'e, France) and protein bands were normalized to the expression of actin in the same sample.

\section{Statistical analysis}

Data analysis was performed with SPSS 17.0. Bar graphs show mean \pm SEM. Data were compared with a one-way analysis of variance (ANOVA) followed by Student-Newman-Keuls post-hoc test. Significant differences were considered when $\mathrm{p}<0.05$.

\section{Results}

\section{Cell Viability}

The cell viability of MitoQ at $0.5 \mu \mathrm{M}$ was similar between 1 and $24 \mathrm{~h}$ of exposure with respect to untreated cells. However, surprisingly, dTPP showed a significant decrease in cell viability at 10 and $24 \mathrm{~h}$, as shown in Supplementary Fig. 1 (all supplementary material available online at www.cellphysiolbiochem. com).

\section{Glucose-induced insulin secretion (GIIS)}

Stimulation with $15 \mathrm{mM}$ glucose plus treatment with MitoQ significantly increased insulin secretion with respect to stimulation with $3 \mathrm{mM}$ glucose under normo-lipidic conditions (Fig. 1). This incremental effect of 15 versus $3 \mathrm{mM}$ glucose was $86.7 \%$ when mitoQ was present versus $20.5 \%$ in control conditions. In contrast, there were no significant differences in insulin secretion in the lipidic environment.

In addition, in the normo-lipidic environment there was a trend toward a greater release of insulin at $15 \mathrm{mM}$ glucose in the mito $Q$ versus control group $(p=0.115)$.

\section{Mitochondrial Function}

An $\mathrm{O}_{2}$ electrode was used to monitor the rate of $\mathrm{O}_{2}$ consumption in INS-1E $\beta$ cells treated with and without MitoQ. $\mathrm{O}_{2}$ consumption by the cells was mainly mitochondrial, since addition of sodium cyanide resulted in almost complete (95-99\%) inhibition of $\mathrm{O}_{2}$

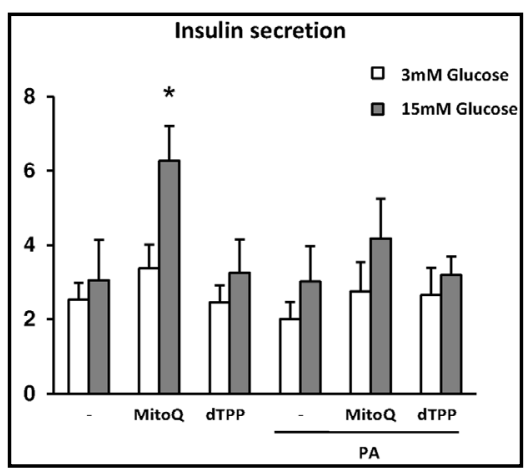

Fig. 1. Effects of MitoQ on insulin secretion in INS-1E cells exposed to glucose or palmitate conditions. Cells were incubated in the presence or absence of $0.5 \mathrm{mM}$ palmitate for $24 \mathrm{~h}$ and then exposed to MitoQ for $3 \mathrm{~h}$. Subsequently, they were incubated in HBSS containing $3 \mathrm{mM}$ or $15 \mathrm{mM}$ glucose. Insulin secretion was evaluated by measuring insulin concentrations in the conditioned medium with an ELISA assay. Data are expressed as insulin secretion in total protein content (mean \pm SEM, $n=8-11$ ) . ${ }^{*} \mathrm{p}<0.05$ with regard to MitoQ-treated cells in the $3 \mathrm{mM}$ glucose condition. 
Escribano-Lopez et al:: MitoQ Alleviates Endoplasmic Reticulum Stress Under Hyperglycaemia

consumption (not shown). Rates of $\mathrm{O}_{2}$ consumption in $\beta$ cells, whether treated or not with MitoQ, remained constant under NG. Interestingly, although HG enhanced $\mathrm{O}_{2}$ consumption rates $(\mathrm{p}<0.05)$, MitoQtreated $\beta$ cells showed a downward trend under these conditions (Fig. 2A and 2B). In the lipidic environment, the response of MitoQ to $\mathrm{O}_{2}$ consumption was attenuated with respect to the HG condition, although there was a trend towards an improvement $(p=0.100)$ when we compared the PA condition without vs with MitoQ for $3 \mathrm{~h}$. These results did not change when cells were exposed to MitoQ for $24 \mathrm{~h}$ (Supplementary Fig. 2A). Similarly, no changes were observed with respect to $\Delta \Psi \mathrm{m}$, measured as TMRM fluorescence, in any of the conditions studied (Fig. 2C).

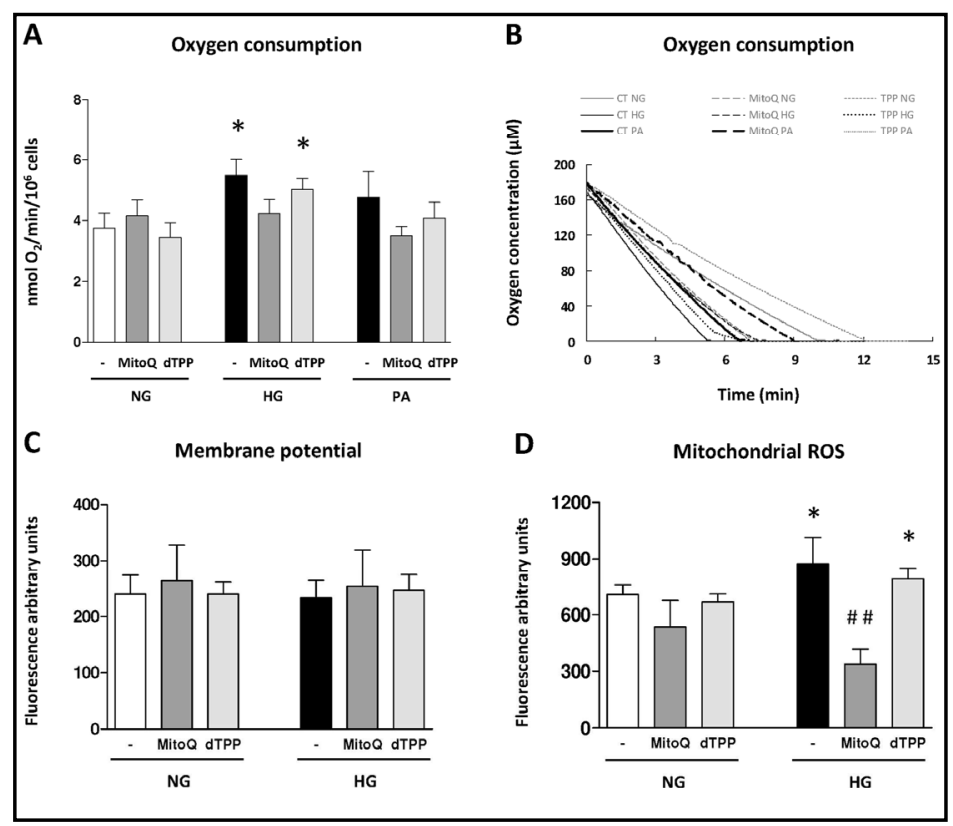

Fig. 2. Evaluation of mitochondrial function in INS-1E cells under normoglycaemia and hyperglycaemia in the presence and absence of

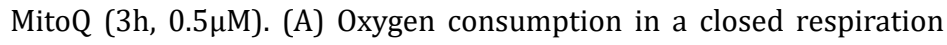
chamber measured as $\mathrm{nmol} \mathrm{O}_{2} / \mathrm{min} / 10^{6}$ cells. (B) Representative traces showing the rate of $\mathrm{O}_{2}$ consumption in a closed respiration chamber. (C) Mitochondrial membrane potential measured as TMRM fluorescence by fluorometry. (D) Mitochondrial ROS production measured as MitoSOX fluorescence by fluorometry. ${ }^{*} \mathrm{p}<0.05$ with regard to control in normoglycaemia. ${ }^{\# \#} \mathrm{p}<0.01$ when comparing groups treated and not treated with MitoQ in the hyperglycaemic condition (data represented as mean $\pm S E M, n=6$ ).

higher levels of MitoSOX

oxidation under HG than under NG conditions, which was consistent with an increase in mitochondrial ROS production; however, MitoQ decreased MitoSOX oxidation specifically in cells cultured under HG conditions (Fig. 2D, $p<0.01$ ).

None of these oxidative stress parameters was affected by treatment with the control compound decyl-TPP, which has the same mitochondrial-targeting moiety as MitoQ but lacks an antioxidant effect.

\section{Oxidative stress parameters}

Total ROS fluorescence, evaluated by DCFH-DA fluorescence, was significantly higher in untreated cells under HG with respect to $\mathrm{NG}(\mathrm{p}<0.05)$. Interestingly, MitoQ treatment decreased total ROS $(\mathrm{p}<0.05)$ to values similar to those observed under NG conditions, thus revealing a decrease in oxidative stress under HG. MitoQ did not alter total ROS in INS-1E $\beta$ cells under NG (Fig. 3A).

On the other hand, CMFDA fluorescence, which is proportional to the content of the free thiol form of GSH in INS-1E $\beta$ cells, decreased under HG $(\mathrm{p}<0.05)$ and was restored in the presence of MitoQ $(\mathrm{p}<0.05)$, suggesting a protective role. MitoQ did not alter the levels of GSH in NG conditions (Fig. 3B).

These results demonstrate that HG conditions induce oxidative stress in INS-1E $\beta$ cells and that MitoQ prevents this effect by reducing levels of ROS and preserving antioxidant content. We can also confirm that none of the oxidative stress parameters was affected by treatment with the control compound decyl-TPP. 


\section{Cellular Physiology Cell Physiol Biochem 2018;52:186-197 \\ \begin{tabular}{ll|l} 
and Biochemistry & DOl: 10.33594/000000013 & $\begin{array}{l}\text { O 2019 The Author(s). Published by } \\
\text { Published online: } 28 \text { February } 2019 \\
\text { Cell Physiol Biochem Press GmbH\&Co. KG }\end{array}$ \\
\cline { 2 - 3 }
\end{tabular} \\ Escribano-Lopez et al.: MitoQ Alleviates Endoplasmic Reticulum Stress Under \\ Hyperglycaemia}

\section{ER stress}

As oxidative stress is closely related to ER stress, we investigated whether the unfolded protein response (UPR) was activated in INS-1E $\beta$-cells by assessing protein levels of the ER stress markers GRP78 and P-eIF2 $\alpha$.

INS-1E $\beta$ cells cultured under HG displayed enhanced protein levels of the glucoseregulated protein 78 (GRP78) chaperone (Fig. 4A) and phosphorylated eukaryotic translation initiation factor 2 alpha (P-eIF $\alpha$, Fig. 4B) with respect to control cells $(\mathrm{p}<0.01)$, which pointed to activation of the UPR. These effects under HG conditions were reversed by addition of MitoQ ( $\mathrm{p}<0.01$, Fig. 4A and 4B), which did not modify protein levels in NG or PA conditions. However, although there was no significant difference in GRP78 in the lipidic condition, there was a trend $(\mathrm{p}=0.147)$ towards a decrease when cells were exposed

Fig. 3. Effects of MitoQ (3h, 0.5 $\mu \mathrm{M})$ on oxidative stress parameters in pancreatic $\beta \quad$ cells under norm o gly c a e m i a and hyperglycaemia. (A) ROS production measured as DCFHDA fluorescence by fluorometry. (B) GSH

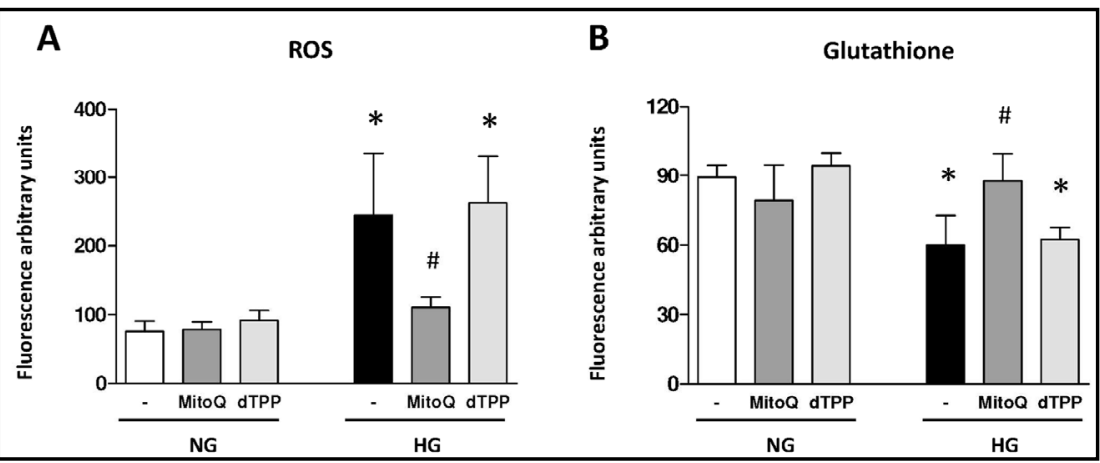
levels measured as CMFDA fluorescence by fluorometry. ${ }^{*} \mathrm{p}<0.05$ with regard to control in normoglycaemia. ${ }^{\#} \mathrm{p}<0.05$ comparing groups treated and not treated with MitoQ in the hyperglycaemic condition (data represented as mean \pm S.E.M, $n=6$ ).

Fig. 4. Evaluation of endoplasmic reticulum stress markers in pancreatic $\quad \beta \quad$ cells under normoglycaemia, hyperglycaemia and lipidic conditions in the presence and absence of MitoQ (3h, 0.5 $\mathrm{M}$ ). (A) Protein levels of GRP78 and representative $\mathrm{WB}$ images. (B) Protein levels of P-eIF2 $\alpha$ and representative $\mathrm{WB}$ images. (C) Levels of intracellular calcium measured as Fluo-4 AM fluorescence by fluorometry. $\quad * \mathrm{p}<0.05$ and $\quad * * \mathrm{p}<0.01 \quad$ with regard to control in nor m o g ly c a e m i a. ${ }^{\#} \mathrm{p}<0.05$, ${ }^{\# \#} \mathrm{p}<0.01$ when comparing groups treated and not treated

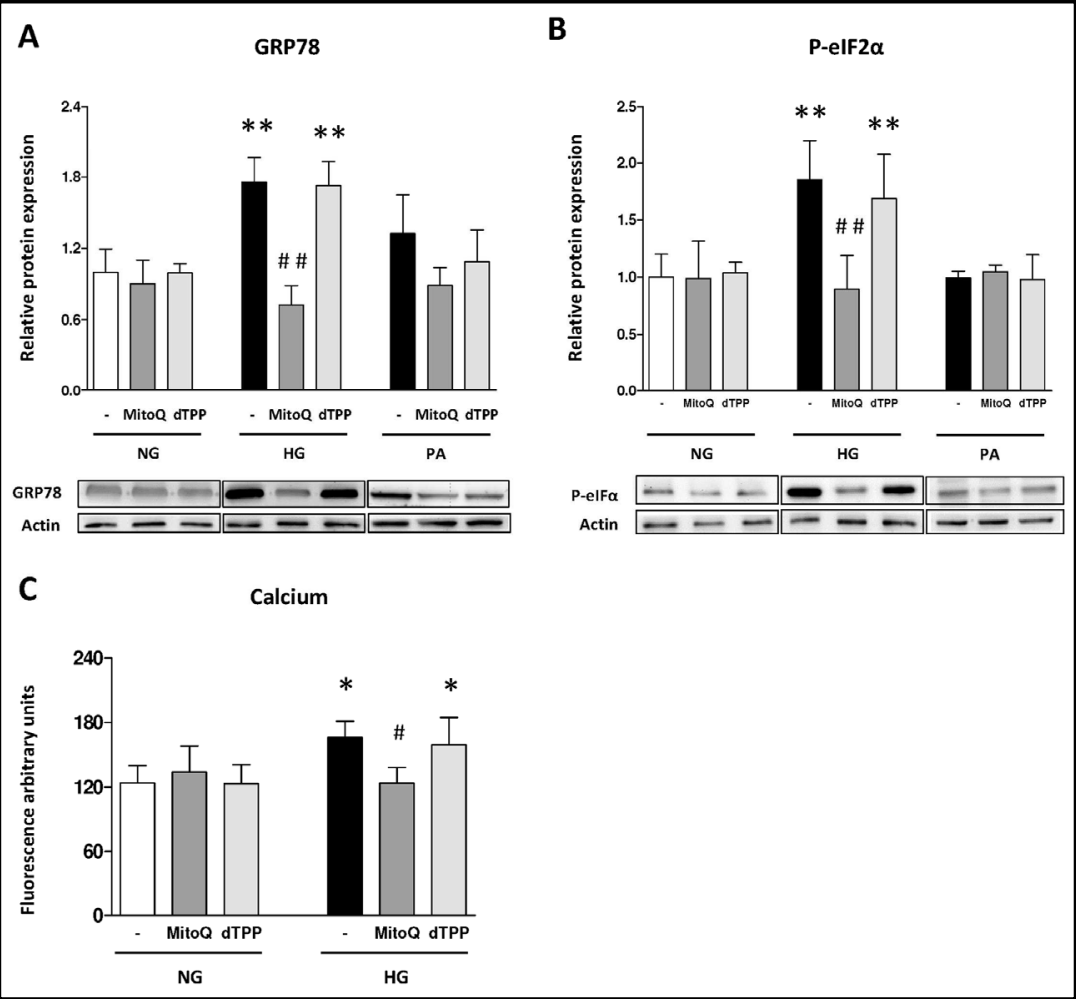
with MitoQ in the hyperglycaemia condition (data represented as mean \pm S.E.M, $n=6$ ). 


\section{Cellular Physiology \\ \begin{tabular}{ll|l} 
and Biochem $10.33594 / 000000013$ & C 2019 The Author(s). Published by \\
Cell Physiol Biochem Press GmbH\&Co. KG
\end{tabular} \\ Escribano-Lopez et al.: MitoQ Alleviates Endoplasmic Reticulum Stress Under \\ Hyperglycaemia}

to MitoQ. No changes were observed with respect to ER stress markers after 24h exposure to MitoQ in any of the conditions studied (Supplementary Fig. 2B and 2C).

Fluo4-AM fluorescence, employed to measure calcium content, followed a similar pattern to that of ER stress proteins. Whereas calcium levels remained constant in INS-1E $\beta$ cells with or without MitoQ under NG conditions, there was an increase in intracellular calcium levels in the HG condition that was reverted in the presence of MitoQ, suggesting a preventive effect (Fig. 4C). Decyl-TPP treatment did not affect any of these parameters.

\section{Levels of NFK $\beta$-p65 (phospho S536)}

INS-1E $\beta$ cells showed an increase in NFкB-p65 levels (Fig. 5, p<0.01) under $\mathrm{HG}$ conditions, but MitoQ treatment returned NFKB-p65 protein levels to those observed under NG conditions (Fig. 5, p<0.01), thus suggesting an anti-inflammatory effect. MitoQ did not modify NFkB-p65 levels under NG or PA conditions. Decyl-TPP treatment did not affect NFкB-p65 protein expression. No changes were observed with respect to NFKB after $24 \mathrm{~h}$ exposure to MitoQ (Supplementary Fig. 2D).

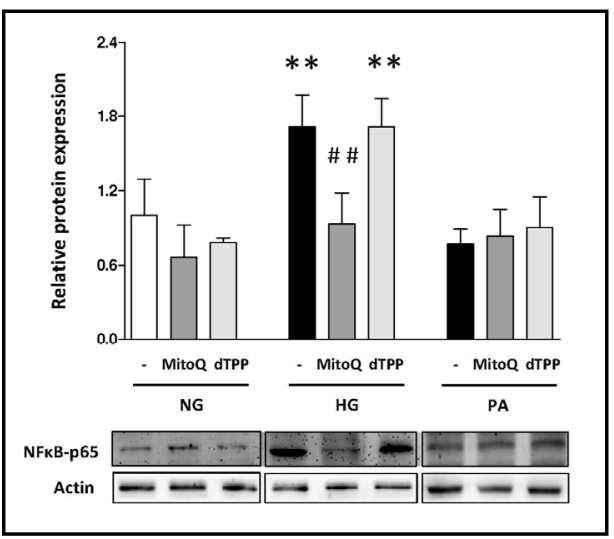

Fig. 5. Evaluation of NFkB-p65 (phospho S536) protein expression in pancreatic $\beta$ cells under normoglycaemia, hyperglycaemia and lipidic conditions in the presence and absence of MitoQ (3h, $0.5 \mu \mathrm{M})$. Protein levels of NFkB-p65 and representative WB images. ${ }^{* *} \mathrm{p}<0.01$ with regard to control in normoglycaemia. ${ }^{\# \#} \mathrm{p}<0.01$ comparing groups treated and not treated with MitoQ in the hyperglycaemia condition (data represented as mean \pm S.E.M, $n=6$ ). Protein expression of NFkB-p65 (phospho S536) was assessed in the total cell protein extract.

\section{Discussion}

In the present study we demonstrate that HG induces an increase of mitochondrial oxygen consumption, mitochondrial ROS production, the ER stress markers GRP78 and P-eIF2 $\alpha$, calcium levels and NFKB-p65 protein expression in pancreatic $\beta$ cells, while HG, in contrast, decreases GSH levels in said cells. In addition, we demonstrate the potential beneficial effects of the mitochondrial antioxidant MitoQ, which appears to restore conditions after its administration.

INS-1E is a cell line that displays stable glucose responsiveness and closely mimics the function of normal pancreatic islets. In addition, INS-1E cells are responsive to potentiators of glucose signalling, which makes them useful for studying the mechanisms involved in the regulation of insulin secretion. They are particularly suitable for testing potential therapeutic agents for diabetes treatment, such as mitochondrial-targeted antioxidants [27]. In this sense, our present data demonstrate that MitoQ treatment together with high glucose stimulation significantly increases insulin secretion, suggesting an improvement of $\beta$ cell function.

HG is closely related to oxidative stress and mitochondrial dysfunction [28, 29]. In fact, we have previously demonstrated that leukocytes from T2D patients present oxidative stress, mitochondrial dysfunction and ER stress [28]. Furthermore, different studies have shown the beneficial effects of mitochondrial antioxidant enzymes under HG, as they protect against oxidative stress [30]. In light of this knowledge, we set out to assess whether mitochondriatargeted antioxidants exert beneficial effects under HG, as previously demonstrated in leukocytes from T2D patients in our laboratory [31]. In fact, MitoQ has been shown to be an effective therapeutic strategy for diabetic nephropathy in the Ins2 ${ }^{+/ \text {-Akital }}$ mouse model [18], and promotes the survival and function of pancreatic $\beta$ cells when they are subjected 


\section{Cellular Physiology Cell Physiol Biochem 2018;52:186-197 \\ \begin{tabular}{ll|l} 
and Biochemistry & $\begin{array}{l}\text { DOl: } 10.33594 / 000000013 \\
\text { Published online: } 28 \text { February } 2019\end{array}$ & $\begin{array}{l}\text { C } 2019 \text { The Author(s). Published by } \\
\text { Cell Physiol Biochem Press GmbH\&Co. KG }\end{array}$
\end{tabular} \\ Escribano-Lopez et al.: MitoQ Alleviates Endoplasmic Reticulum Stress Under \\ Hyperglycaemia}

to glucotoxicity and glucolipotoxicity by improving insulin secretion [32]. In addition to the above, we selected MitoQ for the present study due to its biocompatibility and safety at levels whose efficacy has been demonstrated previously, and again in this work. Previous studies have shown that $\mathrm{TPP}^{+}$compounds, such as MitoQ, when used at typical culture concentrations, can affect mitochondrial function depending on the linker group but not on antioxidant properties [33]. Under our conditions, MitoQ did not disrupt mitochondrial function and the decyl-TPP control compound was not protective. It is important to highlight that Mito $Q$ can concentrate rapidly in mitochondria several 100 -fold due to its high membrane potential, which helps to prevent lipid peroxidation. MitoQ does not react with $\mathrm{H}_{2} \mathrm{O}_{2}$ or $\mathrm{H}_{2} \mathrm{O}_{2}$ radicals, but does so with $\mathrm{O}_{2}-$, among other radical oxygen and carbon species. The fact that MitoQ can prevent lipid peroxidation highlights the important role of this compound under oxidative stress conditions [34]. In addition, MitoQ is oriented with the $\mathrm{TPP}^{+}$moiety near the membrane surface, accessing the membrane core to act as a chain-breaking antioxidant and allowing recycling of MitoQ to its ubiquinol form via reduction by complex II [35].

HG and hyperlipidaemia are related to mitochondrial ROS production in pancreatic $\beta$ cells during T2D [7, 32]. In fact, $\beta$ cells are particularly susceptible to damage by ROS because of their reduced expression of antioxidant enzymes [36]. In relation to this, the results of the present study show that treatment with MitoQ reduces mitochondrial $\mathrm{O}_{2}$ consumption under HG conditions, as well as total and mitochondrial ROS, and enhances GSH levels, thus exerting an antioxidant effect. These results are in line with those of previous studies showing that MitoQ reduces ROS and modulates antioxidant activities such as glutathione peroxidase (GPX1) under oxidative stress conditions in propionic acidemia patient-derived fibroblasts [37] and in leukocytes from T2D patients [31]. Moreover, mitochondria-targeted antioxidants have also been shown to maintain mitochondrial morphology, to restore intracellular ATP levels and to increase $\beta$ cell survival under glucotoxic and glucolipotoxic conditions [32].

It is well known that ER stress and oxidative stress are related $[28,38]$, which in turn links ER stress to mitochondrial ROS. In this sense, several studies have focused on the contribution of ER stress to the development of insulin resistance and T2D [39, 40]. In this sense, it has been described that autophagy can regulate insulin resistance following ER stress in diabetes [41]. In addition, ER stress has been implicated in apoptosis of pancreatic $\beta$ cells in a diabetic mouse model [42], and of leukocytes in T2D patients [28, 43]. In addition, Sage et al. [44] showed GRP78, sXBP1 and CHOP levels to be positively correlated with glucose levels in leukocytes from patients with metabolic syndrome. In accordance with these data, our present findings demonstrate that HG enhances levels of ER stress markers such as GRP78 and P-eIF2 $\alpha$, and intracellular calcium levels. Interestingly, MitoQ treatment reversed these effects, suggesting that this molecule ameliorates the mitochondrial disruption which leads to ER stress. Furthermore, under lipidic conditions, levels of GRP78 were increased, although not significantly, while MitoQ partially reversed this effect. In this sense, it has been described that palmitate causes impaired $\beta$-oxidation and citric acid cycle flux, suggesting that this undermined mitochondrial metabolism has important implications for metabolic diseases such as type 2 diabetes [45]. In addition, ER stress/UPR activation plays a critical role in lipid metabolism and homeostasis. ER stress-dependent dysregulation of lipid metabolism may lead to dyslipidemia, insulin resistance, cardiovascular disease, type 2 diabetes, and obesity [46].

It is well known that oxidative stress leads to pro-inflammatory responses. Specifically, it has been reported that an increase of ROS production can activate the pro-inflammatory nuclear factor $\mathrm{NF} \mathrm{KB}$, thus contributing to insulin resistance $[47,48]$. In this sense, we have previously reported a significant increase in $\mathrm{NF \kappa B}$ expression in leukocytes of T2D patients [31]. For this reason, we decided to explore whether the antioxidant MitoQ has an effect on p65-NFkB protein expression in pancreatic $\beta$ cells under $\mathrm{HG}$ and lipidic conditions. Although we have assessed the expression of p65 (phospho S563) in total cell protein extracts rather than in nuclear extracts, our results show an increase in the protein NFkB-p65 under HG, which was reverted in the presence of MitoQ. This identifies MitoQ as a mitochondrial 


\section{Cellular Physiology Cell Physiol Biochem 2018;52:186-197 \\ \begin{tabular}{ll|l} 
and Biochemistry & $\begin{array}{l}\text { DOl: 10.33594/000000013 } \\
\text { Published online: } 28 \text { February } 2019\end{array}$ & $\begin{array}{l}\text { O } 2019 \text { The Author(s). Published by } \\
\text { Cell Physiol Biochem Press GmbH\&Co. KG }\end{array}$ \\
\cline { 2 - 3 }
\end{tabular} \\ Escribano-Lopez et al.: MitoQ Alleviates Endoplasmic Reticulum Stress Under \\ Hyperglycaemia}

antioxidant capable of modulating, not only oxidative stress and ER stress, but also the inflammatory response. IKK-mediated S536 phosphorylation is critical for activation of the canonical NFKB pathway. In previous research, Day et al. found that IKK-dependent S536 phosphorylation was also required for RelA/p65 nuclear translocation, acetylation in the nucleus, and, thus, NFKB activation induced by HDAC inhibitors [49]. Furthermore, earlier studies have demonstrated that glucose intolerance in obese mice is attenuated after inhibition of the IKK $\beta / \mathrm{NFKB}$ pathway [50], which suggests this signaling pathway is a central player in the development of T2D. For this reason, we foresee MitoQ treatment as an option for the prevention and/or treatment of insulin resistance and, hence, T2D.

\section{Conclusion}

Overall, our findings provide a better understanding of the pathophysiological mechanisms at work in pancreatic $\beta$ cells under HG. Importantly, our data show that treatment with MitoQ modulates insulin secretion, mitochondrial function, ER stress and the NFKB signalling pathway, suggesting that this compound exerts beneficial effects that can be taken advantage of to improve pancreatic $\beta$ cell function.

\section{Abbreviations}

$\triangle \Psi \mathrm{m}$ (mitochondrial membrane potential); CMFDA (5-chloromethylfluorescein diacetate); DCFH-DA (2',7'-dichlorodihydrofluorescein diacetate); ER (endoplasmic reticulum); FCS (fetal calf serum); Fluo-4 (AM, (acetyloxy)me-thyl ester); GIIS (Glucoseinduced insulin secretion); GRP78 (glucose-regulated protein 78 chaperone); GSH (gluthatione); HG (hyperglycaemia); INS-1E (pancreatic $\beta$ cells isolated from insulinoma; MitoQ mitoquinone); MTT ( 3-(4, 5-dimethylthiazol-2-yl)-2, 5-diphenyltetrazolium bromide); NFKB (nuclear factor kappa B); NG (normoglycaemia); PA (palmitic acid); P-eIF2 $\alpha$ (phosphorylated eukaryotic translation initiation factor 2 alpha); ROS (reactive oxygen species); TMRM (tetramethylrhodamine methylester); T2D (type 2 diabetes); TPP (triphenylphosphonium); UPR (unfolded protein response); WB (western blotting).

\section{Acknowledgements}

The authors thank Brian Normanly (University of Valencia/CIBERehd) for his editorial assistance; and Rosa Falcón and Carmen Ramirez (FISABIO) for their technical assistance. This study was financed by grants PI15/1424, PI16/1083, PI16/0301, and CIBERehd CB06/04/0071 by Carlos III Health Institute, PROMETEOII 2014/035 from the Regional Ministry Education of Valencian Community and by the European Regional Development Fund (ERDF "A way to build Europe"); UGP15-193 and UGP-15-220 by FISABIO. I.E.-L. is recipient of a predoctoral contract from FISABIO (UGP-15-144). N.D.-M. is a recipient of PFIS contracts from Carlos III Health Institute (FI14/00125). F.I is recipient of contract from Generalitat Valenciana GRISOLIAP/2016/015. S.R-L. is recipient of a Juan de la CiervaFormación contract from the Spanish Ministry of Economy and Competitiveness (FJCI-201525040). V.M.V. and M.R. are recipients of contracts from the Ministry of Health of the Valencian Regional Government and Carlos III Health Institute (CES10/030 and CPII16/00037, respectively). Work in M.P.M.'s lab is supported by the Medical Research Council UK (MC_ U105663142) and by a Wellcome Trust Investigator award (110159/Z/15/Z). Unrestricted grant from Menarini S.A. 


\section{Cellular Physiology Cell Physiol Biochem 2018;52:186-197 \begin{tabular}{ll|l} 
and Bioc 2019 The Author(s). Published by \\
\hline
\end{tabular} and BIOChemistry $\frac{\text { Published online: } 28 \text { February } 2019 \text { Cell Physiol Biochem Press GmbH\&Co. KG }}{\text { Escribano-Lopez et al.: MitoQ Alleviates Endoplasmic Reticulum Stress Under }}$ \\ Hyperglycaemia}

\section{Disclosure Statement}

The authors declare that no conflicts of interest exist.

\section{References}

1 Leahy JL: Pathogenesis of type 2 diabetes mellitus. Arch Med Res 2005;36:197-209.

- 2 Butler AE, Janson J, Bonner-Weir S, Ritzel R, Rizza RA, Butler PC: Beta-cell deficit and increased beta-cell apoptosis in humans with type 2 diabetes. Diabetes 2003;52:102-110.

- 3 Prentki M, Nolan CJ Islet beta cell failure in type 2 diabetes. J Clin Invest 2006;116:1802-1812.

- 4 Green K, Brand MD, Murphy MP: Prevention of mitochondria oxidative damage as a therapeutic strategy in diabetes. Diabetes 2004;5:S110-S118.

5 Sivitz WI, Yorek MA: Mitochondrial dysfunction in diabetes: from molecular mechanisms to functional significance and therapeutics opportunities. Antioxid Redox Signal 2010;12:537-577.

- 6 Díaz-Morales N, Rovira-Llopis S, Bañuls C, López-Domenech S, Escribano-López I, Veses S, Jover A, Rocha M, Hernández-Mijares A, Víctor VM: Does metformin protect diabetic patients from oxidative stress and leukocyte-endothelium interactions? Antioxid Redox Signal 2017;27:1439-1445.

- 7 Nishikawa T, Araki E: Impact of mitochondrial ROS production in the pathogenesis of diabetes mellitus and its complications. Antioxid Redox Signal 2007;9:343-353.

- 8 Kaneto H, Katakami N, Matsuhisa M, Matsuoka TA: Role of reactive oxygen species in the progression of type 2 diabetes and atherosclerosis. Mediators Inflamm 2010;2010:453892.

- 9 Lowell BB, Shulman GI: Mitochondrial dysfunction and type 2 diabetes. Science 2005;307:384-387.

- 10 Korshunov SS, Skulachev VP, Starkov AA: High protonic potential actuates a mechanism of production of reactive oxygen species in mitochondria. FEBS Lett 1997;416:15-18.

11 Gorasia DG, Dudek NL, Veith PD, Shankar R, Safavi-Hemami H, Williamson NA, Reynolds EC, Hubbard MJ, Purcell AW: Pancreatic beta cells are highly susceptible to oxidative and ER stresses during the development of diabetes. J Proteome Res 2015;14:688-699.

- 12 Plaisance V, Brajkovic S, Tenenbaum M, Favre D, Ezanno H, Bonnefond A, Bonner C, Gmyr V, Kerr-Conte J, Gauthier BR, Widmann C, Waeber G, Pattou F, Froguel P, Abderrahmani A: Endoplasmic reticulum stress links oxidative stress to impaired pancreatic beta cell function caused by human oxidized LDL. PLoS One 2016;11:E0163046.

- 13 Akerfeldt MC, Howes J, Chan JY, Stevens VA, Boubenna N, McGuire HM, King C, Biden TJ, Laybutt DR: Cytokine-induced beta-cell death is independent of endoplasmic reticulum stress signalling. Diabetes 2008;57:3034-3044.

- 14 Preston AM, Gurisik E, Bartley C, Laybutt DR, Biden TJ: Reduced endoplasmic reticulum (ER)-to-Golgi protein trafficking contributes to ER stress in lipotoxic mouse beta cells by promoting protein overload. Diabetologia 2009;52:2369-2373.

15 Eizirik DL, Cardozo AK, Cnop M: The role for endoplasmic reticulum stress in diabetes mellitus. Endocr Rev 2008;29:42-61.

16 Sanson M, Augé N, Vindis C, Muller C, Bando Y, Thiers JC, Marachet MA, Zarkovic K, Sawa Y, Salvayre R, Nègre-Salvayre A: Oxidized low-density lipoproteins trigger endoplasmic reticulum stress in vascular cells: prevention by oxygen-regulated protein 150 expression. Circ Res 2009;104:328-336.

17 Brownlee M: Biochemistry and molecular cell biology of diabetic complications. Nature 2001;414:813-820.

18 Chacko BK, Reily C, Srivastava A, Johnson MS, Ye Y, Ulasova E, Agarwal A, Zinn KR, Murphy MP, Kalyanaraman B, Darley-Usmar V: Prevention of diabetic nephropathy in Ins2(+/) (AkitaJ) mice by the mitochondria-targeted therapy MitoQ. Biochem J 2010;432:9-19.

- 19 Apostolova N, Victor VM: Molecular strategies for targeting antioxidants to mitochondria: therapeutic implications. Antioxid Redox Signal 2015;22:686-729.

- 20 James AM, Sharpley MS, Manas ARB, Frerman FE, Hirst J, Smith RAJ, Murphy MP: Interaction of the mitochondria targeted antioxidant MitoQ with phospholipid bilayers and ubiquinone oxidoreductases. J Biol Chem 2007;282:14708-14718. 


\section{Cellular Physiology Cell Physiol Biochem 2018;52:186-197 \begin{tabular}{l|l|l}
\cline { 2 - 3 } DOI: 10.33594/000000013 & (2019 The Author(s). Published by
\end{tabular} and BiOChemistry Published online: 28 February 2019 Cell Physiol Biochem Press GmbH\&Co. KG \\ Escribano-Lopez et al.: MitoQ Alleviates Endoplasmic Reticulum Stress Under Hyperglycaemia}

21 Murphy MP, Smith RAJ: Targeting antioxidants to mitochondria by conjugation to lipophilic cations. Annu Rev Pharmacol Toxicol 2007; 47:629-656.

- 22 Sarre A, Gabrielli J, Vial G, Leverve XM, Assimacopoulos-Jeannet F: Reactive oxygen species are produced at low glucose and contribute to the activation of AMPK in insulin-secreting cells. Free Radic Biol Med 2012;52:142-150.

- 23 Brun T, Scarcia P, Li N, Gaudet P, Duhamel D, Palmieri F, Maechler P: Changes in Mitochondrial Carriers Exhibit Stress-Specific Signatures in INS-1E $\beta$-cells Exposed to Glucose Versus Fatty Acids. PlosOne 2013;8:E82364.

- 24 Natalicchio A, Biondi G, Marrano N, Labarbuta R, Tortosa F, Spagnuolo R, D’Oria R, Carchia E, Leonardini A, Cignarelli A, Perrini S, Laviola L, Giorgino F: Long-term exposure of pancreatic $\beta$-cells to palmitate results in DREBP-1C-dependent decreases in GLP-1 receptor signalling via CREB and AKT and insulin secretory response. Endocrinology 2016;157:2243-2258.

- 25 Murphy MP: Targeting lipophilic cations to mitochondria. Biochim Biophys Acta 2008;1777:1028-1031.

- 26 Víctor VM, Rocha M, Bañuls C, Sánchez-Serrano M, Solá E, Gómez M, Hernández-Mijares A: Mitochondrial complex I impairment in leukocytes from polycystic ovary syndrome patients with insulin resistance. J Clin Endocrinol Metab 2009;94:3505-3512.

27 Hohmeier HE, Mulder H, Henkel-Rieger R, Prentki M, Newgard CB: Isolation of INS-1-derived cell lines with robust ATP-sensitive $\mathrm{K}+$ channel-dependent and independent glucose-stimulated insulin secretion. Diabetes 2000;49:424-430.

- 28 Rovira-Llopis S, Bañuls C, Apostolova N, Morillas C, Hernández-Mijares A, Rocha M, Víctor VM: Is glycemic control modulating endoplasmic reticulum stress in leukocytes of type 2 diabetic patients? Antioxid Redox Signal 2014;21:1759-1765.

- 29 Leverve XM, Guigas B, Detaille D, Batandier C, Koceir EA, Chauvin C, Fountaine E, Wiernsperger NF: Mitochondrial metabolism and type 2 diabetes: a specific target of metformin. Diabetes Metab 2003;29:6S88-6S94.

- 30 Kowluru RA, Kowluru V, Xiong Y, Ho YS: Overexpression of mitochondrial superoxide dismutase in mice protects the retina from diabetes-induced oxidative stress. Free Radic Biol Med 2006;41:1191-1196.

- 31 Escribano-López I, Díaz-Morales N, Rovira-Llopis S, Martínez De Marañón A, Orden S, Alvarez A, Bañuls C, Rocha M, Hernández-Mijares A, Víctor VM: The mitochondria-targeted antioxidant MitoQ modulates oxidative stress, inflammation and leukocyte-endothelium interactions in leukocytes isolated from type 2 diabetic patients. Redox Biology 2016;10:200-205.

32 Lim S, Rashid MA, Jang M, Kim Y, Won H, Lee J, Woo JT, Kim YS, Murphy MP, Ali L, Ha J, Kim SS: Mitochondria-targeted antioxidants protect pancreatic $\beta$-cells against oxidative stress and improve insulin secretion in glucotoxicity and glucolipotoxicity. Cell Physiol Biochem 2011;28:873-886.

- 33 Reily C, Mitchell T, Chacko BK, Benavides G, Murphy MP, Darley-Usmar V: Mitochondrially targeted compounds and their impact on cellular bioenergetics. Redox Biol 2013;1:86-93.

- 34 Murphy MP, Smith RA: Targeting antioxidants to mitochondria by conjugation to lipophilic cations. Annu Rev Pharmacol Toxicol 2007;47:629-656.

- 35 James AM, Sharpley MS, Manas AR, Frerman FE, Hirst J, Smith RA, Murphy MP: Interaction of the mitochondria-targeted antioxidant MitoQ with phospholipid bilayers and ubiquinone oxidoreductases. J Biol Chem 2007;282:14708-14718.

- 36 Tiedge M, Lortz S, Drinkgern J, Lenzen S: Relation between antioxidant enzyme gene expression and antioxidative defense status of insulin-producing cells. Diabetes 1997;46:1733-1742.

37 Gallego-Villar L, Pérez B, Ugarte M, Desviat LR, Richard E: Antioxidants successfully reduce ROS production in propionic acidemia fibroblasts. Biochem Biophys Res Commun 2014;452:457-461.

38 Zhang Y, Soboloff J, Zhu Z, Berger SA: Inhibition of $\mathrm{Ca}^{2+}$ influx is required for mitochondrial reactive oxygen species-induced endoplasmic reticulum $\mathrm{Ca}^{2+}$ depletion and cell death in leukemia cells. Mol Pharmacol 2006;70:1424-1434.

- 39 Ozcan U, Cao Q, Yilmaz E, Lee AH, Iwakoshi NN, Ozdelen E, Tuncman G, Görgün C, Glimcher LH, Hotamisligil GS: Endoplasmic reticulum stress links obesity, insulin action, and type 2 diabetes. Science 2004;306:457461.

- 40 Harding HP, Ron D: Endoplasmic reticulum stress and the development of diabetes: a review. Diabetes 2002;51:S455-S461. 


\section{Cellular Physiology Cell Physiol Biochem 2018;52:186-197

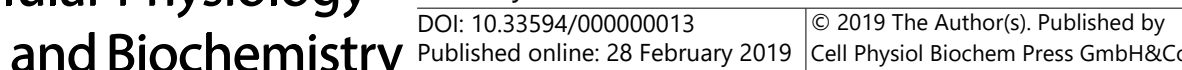 \\ Escribano-Lopez et al.: MitoQ Alleviates Endoplasmic Reticulum Stress Under \\ Hyperglycaemia}

41 Zhang N, Cao MM, Liu H, Xie GY, Li YB: Autophagy regulates insulin resistance following endoplasmic reticulum stress in diabetes. J Physiol Biochem 2015;71:319-327.

- 42 Huang CJ, Haataja L, Gurlo T, Butler AE, Wu X, Soeller WC, Butler PC: Induction of endoplasmic reticulum stress induced beta-cell apoptosis and accumulation of polyubiquitinated proteins by human islet amyloid polypeptide. Am J Physiol Endocrinol Metab 2007;293:E1656-E1662.

43 Komura T, Sakai T, Honda M, Takamura T, Matsushima K, Kaneko S: CD14 + monocytes are vulnerable and functionally impaired under endoplasmic reticulum stress in patients with type 2 diabetes. Diabetes 2010;59:634-643.

44 Sage AT, Holtby-Ottenhof S, Shi Y, Damjanovic S, Sharma AM, Werstuck GH: Metabolic syndrome and acute hyperglycemia are associated with endoplasmic reticulum stress in human mononuclear cells. Obesity (Silver Spring) 2012;20:748-755.

45 Haffar T, Akoumi A, Bousette N: Lipotoxic Palmitate Impairs the Rate of $\beta$-Oxidation and Citric Acid Cycle Flux in Rat Neonatal Cardiomyocytes. Cell Physiol Biochem 2016;40:969-981.

46 Basseri S, Austin RC: Endoplasmic Reticulum Stress and Lipid Metabolism: Mechanisms and Therapeutic Potential. Biochem Res Int 2012;2012:841362.

47 Styskal J, Van Remmen H, Richardson A, Salmon AB: Oxidative stress and diabetes: what can we learn about insulin resistance from antioxidant mutant mouse model? Free Radic Biol Med 2012;52:46-58.

- 48 Rains JL, Jain SK: Oxidative stress, insulin signalling, and diabetes. Free Radic Biol Med 2011;50:567-575.

- 49 Dai Y, Chen S, Wang L, Pei XY, Funk VL, Kramer LB, Dent P, Grant S: Disruption of IkappaB kinase (IKK)mediated RelA serine 536 phosphorylation sensitizes human multiple myeloma cells to histone deacetylase (HDAC) inhibitors. J Biol Chem 2011;286:34036-34050.

50 Benzler J, Ganjam GK, Pretz D, Oelkrug R, Koch CE, Legler K, Stöhr S, Culmsee C, Williams LM, Tups A: Central inhibition of IKK $\beta / N F-\kappa B$ signaling attenuates high-fat diet-induced obesity and glucose intolerance. Diabetes 2015;64:2015-2027. 